\title{
Successful percutaneous coronary intervention for chronic total occlusion via the radial artery
}

\author{
Mustafa Adem Tatlisu \\ Department of Cardiology, Sivas Numune State Hospital, Sivas, Turkey
}

\begin{abstract}
Over the past decade, percutaneous coronary interventions (PCIs) performed via radial artery (RA) access have become popular among interventional cardiologists. Since the radial approach may limit the options in complex cases, most interventional cardiologists prefer femoral access to RA access for complex procedures, such as chronic total occlusions (CTOs) and bifurcation lesions. Presently described is a case of CTO of the right coronary artery that was successfully treated with PCI via the left RA. This study demonstrates that if there is an indication for revascularization and the CTO lesions are short and without poor prognostic factors, an intervention for CTO should still be considered, even if there is no femoral access.
\end{abstract}

Keywords: Chronic total occlusion; percutaneous coronary intervention; transradial approach.

Cite this article as: Tatlisu M. A. Successful percutaneous coronary intervention for chronic total occlusion via the radial artery. North Clin Istanb 2018;5(2):160-162.

$\mathrm{O}$ ver the past decades, percutaneous coronary interventions (PCIs) performed via the radial access (RA) have become popular among interventional cardiologists. In a meta-analysis of PCI studies performed via both RA and femoral access (FA) incorporating many of these studies, better outcomes were obtained with RA than with FA with respect to access site complications, bleeding, and death [1]. Because the radial approach may limit our options in complex cases, most interventional cardiologists prefer the transfemoral approach over the transradial approach for complex procedures such as those for chronic total occlusions (CTOs) and bifurcation lesions.

Here we present a case of CTO of the right coronary artery (RCA) that was successfully treated with PCI via the left radial artery.

\section{CASE REPORT}

A 52-year-old man presented with shortness of breath and stable class III angina for 7 months despite treatment with acetylsalicylic acid (100 mg/day), clopidogrel (75 $\mathrm{mg} /$ day), metoprolol extended-release succinate (200 $\mathrm{mg} /$ day), extended-release isosorbide mononitrate $(60$ $\mathrm{mg} /$ day), modified-release trimetazidine (70 mg/day), telmisartan $(80 \mathrm{mg} / \mathrm{day})$, and rosuvastatin $(40 \mathrm{mg} / \mathrm{day})$. Six year ago, he underwent elective coronary stent placement for symptomatic $80 \%$ stenosis in mid-RCA. His second coronary angiogram was performed at 6 months previously because of an unstable angina. Angiogram revealed that the coronary stent in mid-RCA was completely occluded (Fig. 1A) with Rentrop grade II collaterals from the left anterior descending artery (Fig. 1B). PCI failed, and the patient was prescribed optimal antiischemic therapy that included isosorbide mononitrate and trimetazidine. The patient had a 10-year history of hypertension and a 2-year history of Leriche's syndrome that was treated with aorta-iliac artery bypass. He had been smoking two packs of cigarettes daily for 32 years.

Electrocardiogram of the patient did not reveal any recent ST-segment elevation myocardial infarction. The patient previously underwent myocardial perfusion single

Received: April 04, 2017 Accepted: August 05, 2017 Online: March 27, 2018

Correspondence: Dr. Mustafa Adem TATLISU. Department of Cardiology, Sivas Numune State Hospital, Sivas, Turkey.

Phone: +905364439906 e-mail: ademtatlisu@gmail.com

(c) Copyright 2018 by Istanbul Provincial Directorate of Health - Available online at www.northclinist.com 

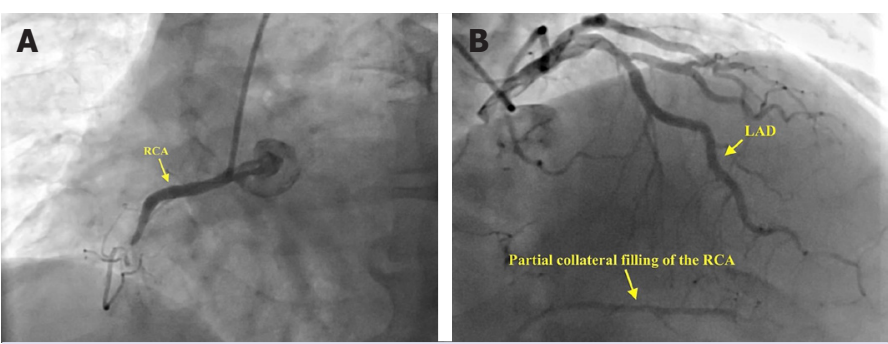

FIGURE 1. (A) Coronary angiogram of the completely occluded right coronary artery. (B) Coronary angiogram showing Rentrop grade II collateral flow to the right coronary artery from the left ascending coronary artery

photon emission computed tomography, which revealed significant viability in the inferior, inferoseptal, and inferolateral walls. Left ventricular function was moderately diminished, with significant wall motion abnormality in the inferior, inferoseptal, and inferolateral walls and a calculated ejection fraction of $40 \%$. Therefore, it was decided that the patient would benefit after undergoing PCI for CTO of RCA.

Because he previously underwent aorta-iliac artery bypass and impalpable right radial pulse, the only option for the procedure was antegrade wire escalation technique via the left radial artery using a 6-Fr right Judkins guiding catheter. The success rate with antegrade wiring and intimal tracking technique is high for short CTOs without proximal cap ambiguity. The Fielder XT ${ }^{\circledR}$-tapered tip 0.009" (Asahi Intecc Co. Ltd., Nagoya-shi, Aichi, Japan) failed to penetrate the hard and calcified proximal cap. However, the proximal CTO cap was eventually penetrated using the Asahi Confianza PROTM 12-tapered tip 0.009" wire (Asahi Intecc Co. Ltd., Nagoya-shi, Aichi, Japan). After predilation using a $1.2-\times 15-\mathrm{mm}$ balloon, the buddy wire technique with Fielder $\mathrm{XT}^{\oplus}$ was used to advance a wider and longer balloon through the lesion. Despite several predilations with $1.5-\times 20-\mathrm{mm}, 2.5-\times 20-\mathrm{mm}$, and $3.0-\times 20-\mathrm{mm}$ balloons, a satisfactory angiographic result was not observed (Fig. $2 \mathrm{~A})$. To achieve better results, the $3.0-\times 15-\mathrm{mm}$ cutting balloon, which resulted in TIMI II flow (Fig. 2B). After an intracoronary injection of nitroglycerin $(100 \mu \mathrm{g})$, two $3.0-\times 38-\mathrm{mm}$ everolimus-eluting coronary stents (Promus ElementTM, Boston Scientific, Marlborough, MA, USA) were used in a telescopic manner to cover the previous stent. After dilation at $20 \mathrm{~atm}$ of pressure via a $3-\times 20-\mathrm{mm}$ NC balloon, the result was satisfactory (Fig. 3 ). During follow-up, the symptoms and exercise capac-
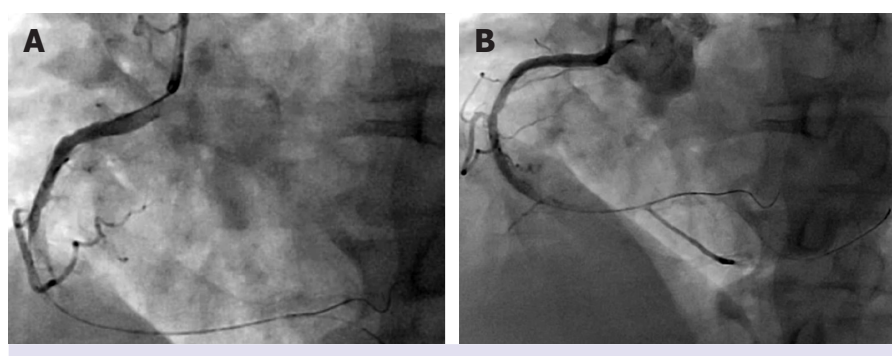

FIGURE 2. (A) Coronary angiogram of the right coronary artery flow before cutting balloon dilatation. (B) Coronary angiogram of the right coronary artery flow after cutting balloon dilatation.
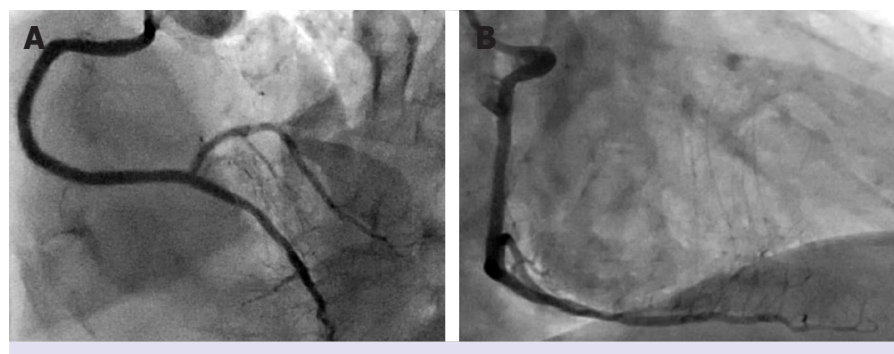

FIGURE 3. Coronary angiogram of the right coronary artery after two overriding coronary stents.

ity of the patients rapidly improved. During follow-up, isosorbide mononitrate and trimetazidine therapies were discontinued. He was advised to quit smoking; however, he continues to smoke. He is currently symptom free for 2.5 years (from July 2014 to March 2017).

\section{DISCUSSION}

Identification of anatomical features of procedural complexity may predict procedural success such as the presence of significant coronary calcium and vessel tortuosity [2]. Several factors are associated with poor procedural success, including the morphology of the proximal cap, presence of bridging collaterals, and length of occlusion [3]. Antegrade wire escalation with intimal tracking should be the preferred initial strategy for short CTOs without poor prognostic factors [4]. Retrograde or antegrade dissection re-entry approach should be reserved for more complex anatomies.

Patients with CTO who remain symptomatic despite optimal medical therapy can be considered for revascularization [5]. In a meta-analysis of long-term clinical outcomes of patients who underwent PCI for CTO, successful PCIs for CTOs were associated with a lower 
risk for death, stroke, and coronary artery bypass grafting and less recurrent angina pectoris [6]. Most recent data showed that PCI may reduce the risk for cardiac mortality in patients without diabetes but not in patients with diabetes [7]. In light of current evidence, the initial decision regarding the mode of revascularization should be based on the symptoms and complexity of lesions.

In this case report, left RA was used to treating CTO owing to the lack of FA, which resulted in successful PCI. If there is an indication for revascularization and CTO lesions are short without poor prognostic factors, an intervention for CTO should be considered even if there is no FA.

Informed Consent: Written informed consent was obtained from the patient who participated in this study.

Conflict of Interest: No conflict of interest was declared by the authors.

Financial Disclosure: The authors declared that this study has received no financial support.

\section{REFERENCES}

1. Bertrand OF, Bélisle P, Joyal D, Costerousse O, Rao SV, Jolly SS, et al. Comparison of transradial and femoral approaches for percutaneous coronary interventions: a systematic review and hierarchical Bayesian meta-analysis. Am Heart J 2012;163:632-48. [CrossRef]

2. Morino Y, Abe M, Morimoto T, Kimura T, Hayashi Y, Muramatsu T, et al. Predicting successful guidewire crossing through chronic total occlusion of native coronary lesions within 30 minutes: the J-CTO (Multicenter CTO Registry in Japan) score as a difficulty grading and time assessment tool. JACC Cardiovasc Interv 2011;4:213-21. [CrossRef]

3. Muramatsu T, Tsuchikane E, Oikawa Y, Otsuji S, Fujita T, Ochiai M, et al. Incidence and impact on midterm outcome of controlled subintimal tracking in patients with successful recanalisation of chronic total occlusions: J-PROCTOR registry. EuroIntervention 2014;10:681-8.

4. Wilson W, Spratt JC. Advances in procedural techniques--antegrade. Curr Cardiol Rev 2014;10:127-44. [CrossRef]

5. Shah PB. Management of coronary chronic total occlusion. Circulation 2011;123:1780-4. [CrossRef]

6. Christakopoulos GE, Christopoulos G, Carlino M, Jeroudi OM, Roesle $\mathrm{M}$, Rangan BV, et al. Meta-analysis of clinical outcomes of patients who underwent percutaneous coronary interventions for chronic total occlusions. Am J Cardiol 2015;115:1367-75 [CrossRef]

7. Choi KH, Yang JH, Song YB, Hahn JY, Choi JH, Gwon HC, et al. Long-term clinical outcomes of patients with coronary chronic totalocclusion treated with percutaneous coronary intervention versusmedical therapy according to presence of diabetes mellitus. EuroIntervention 2017;13:970-7. [CrossRef] 